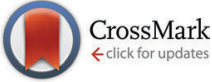

Cite this: Phys. Chem. Chem. Phys., 2015, 17, 5219

Received 12th December 2014 Accepted 8th January 2015

DOI: $10.1039 / c 4 c p 05818 f$

www.rsc.org/pccp

\title{
Electrocapillarity and zero-frequency differential capacitance at the interface between mercury and ionic liquids measured using the pendant drop method
}

\author{
Naoya Nishi,* Atsunori Hashimoto, Eiji Minami and Tetsuo Sakka
}

\begin{abstract}
The structure of ionic liquids (ILs) at the electrochemical IL|Hg interface has been studied using the pendant drop method. From the electrocapillarity (potential dependence of interfacial tension) differential capacitance $\left(C_{d}\right)$ at zero frequency (in other words, static differential capacitance or differential capacitance in equilibrium) has been evaluated. The potential dependence of zero-frequency $C_{d}$ at the $\mathrm{IL} \mid \mathrm{Hg}$ interface exhibits one or two local maxima near the potential of zero charge $\left(E_{\mathrm{pzc}}\right)$, depending on the cation of the ILs. For 1-ethyl-3-methylimidazolium tetrafluoroborate, an IL with the cation having a short alkyl chain, the $C_{d}$ vs. potential curve has one local maximum whereas another IL, 1-octyl-3-methylimidazolium tetrafluoroborate, with the cation having a long alkyl chain, shows two maxima. These behaviors of zerofrequency $C_{d}$ agree with prediction by recent theoretical and simulation studies for the electrical double layer in ILs. At negative and positive potentials far from $E_{\mathrm{pzc}}$, the zero-frequency $C_{d}$ increases for both the ILs studied. The increase in zero-frequency $C_{d}$ is attributable to the densification of ionic layers in the electrical double layer.
\end{abstract}

\section{Introduction}

Ionic liquids (ILs), which are salts composed of entirely ions and are liquid at ambient temperature, have potential applications in electrochemical devices, because of their unique properties such as negligible volatility, low flammability, electrochemical stability, and peculiar solvation toward solutes. ${ }^{1-3}$ For the electrochemical applications of ILs, it is of crucial importance to clarify and to control the interfacial structure and its dependence on the electrode potential. The differential capacitance $\left(C_{\mathrm{d}}\right)$, which is the derivative of surface charge density on the electrode with respect to potential, is a measure of how the structure in the electrical double layer (EDL) responds to the potential change and has been intensively measured and reported at the electrochemical interface of ILs by using electrochemical impedance spectroscopy (EIS). ${ }^{4-13}$ In EIS, a.c. voltage is applied to the electrochemical cell with a frequency, e.g., $1 \mathrm{kHz}$, to evaluate $C_{\mathrm{d}}$. The $C_{\mathrm{d}}$ measured by EIS was confirmed to be equal to the zero-frequency (static) $C_{\mathrm{d}}$ for the $\mathrm{Hg} \mid$ aqueous solution interface, ${ }^{14}$ where the zero-frequency $C_{\mathrm{d}}$ can be evaluated from electrocapillarity, i.e., potential dependence of interfacial tension. For the electrochemical interface of ILs, unlike aqueous solutions, however, this seems not to be the case,

Department of Energy and Hydrocarbon Chemistry, Graduate School of Engineering, Kyoto University, Kyoto 615-8510, Japan. E-mail: nishi.naoya.7e@kyoto-u.ac.jp; Tel: $+81-75-383-2491$ because the structure in EDL of ILs shows ultraslow relaxation in response to the potential change, typically on the order of seconds or minutes ${ }^{15-21}$ which is slower than the time scale of EIS. The ultraslow relaxation leads to deviation of the $C_{\mathrm{d}}$ values obtained by EIS from the zero-frequency $C_{\mathrm{d}}$. In fact, several groups reported frequency dependence of ${C_{\mathrm{d}}}^{18,22-28}$ and hysteresis in potential dependence of $C_{\mathrm{d}}{ }^{22,29-31}$ measured using EIS at the electrochemical interface of ILs. Due to such complications, limitation of EIS to unambiguously measure $C_{\mathrm{d}}$ at the electrochemical interface of ILs has also been discussed. ${ }^{25,32}$ To avoid the confusion caused by frequency dependence of $C_{\mathrm{d}}$, experimental evaluation of zero-frequency $C_{\mathrm{d}}$ for EDL of ILs would be desirable. Theoretical and simulation studies such as mean field theory ${ }^{3,33-35}$ and molecular dynamics (MD) simulations $\mathrm{s}^{36-44}$ always predict zero-frequency $C_{\mathrm{d}}$ (capacitance in equilibrium) and the predicted and experimental zero-frequency $C_{\mathrm{d}}$ could directly be compared and discussed if the latter is available. One of the interesting predictions from the theory is behavior of zerofrequency $C_{\mathrm{d}}$ as a function of electrode potential: bell-shape (one-hump) or camel-shape (two-hump) zero-frequency $C_{\mathrm{d}} v s$. potential curves depending on the compacity of ILs, ${ }^{3,33}$ both of which are totally different from the U-shape curve derived from the Gouy-Chapman theory ${ }^{45,46}$ for conventional electrolyte solutions. This behavior stems from the fact that ions have finite size. Excluded volume not only between an ion at the first ionic layer and the electrode surface but also between two 
neighboring ions has to be considered for EDL of ILs. Furthermore, for the application of ILs to energy storage devices, the zero-frequency $C_{\mathrm{d}}$ reflects the total capacity for energy storage, whereas the high-frequency $C_{\mathrm{d}}$ reflects the power of the devices. Both characteristics are important for such an application, however, experimental data of zero-frequency $C_{\mathrm{d}}$ for the electrochemical IL interface have been unavailable so far.

Here, we will present experimental zero-frequency $C_{\mathrm{d}}$ data at the $\mathrm{IL} \mid \mathrm{Hg}$ interface from electrocapillarity (potential dependence of interfacial tension, $\gamma$ ) measured using the pendant drop method. We used $\mathrm{Hg}$ as an electrode material because the liquid|liquid interface is indispensable to measure $\gamma$ by using the pendant drop method. A good advantage in using $\mathrm{Hg}$ is that we do not have to consider the dependence of $C_{\mathrm{d}}$ on the crystal surfaces and the effective area of the electrode, because an atomically flat interface is spontaneously formed even with capillary waves present at soft interfaces. Electrocapillarity at the $\mathrm{IL} \mid \mathrm{Hg}$ interface has already been reported by several researchers. However, the studies used the drop time method ${ }^{5,6,47-54}$ and the drop weight method, ${ }^{55}$ both of which are "dynamic" methods and have a time scale of several seconds that is much faster than the ultraslow relaxation of the structure in EDL of ILs. Possibly being aware of the time-scale problem, they did not thermodynamically analyze their electrocapillarity data to obtain zerofrequency $C_{\mathrm{d}}$, except two studies ${ }^{53,55}$ where the authors formally fitted polynomial to electrocapillarity data and differentiated it twice to obtain the polynomial function of $C_{\mathrm{d}}$. In the present study, long-time measurements of $\gamma$ by the pendant drop method enabled us to track the ultraslow relaxation of the structure at the IL $\mid \mathrm{Hg}$ interface to the potential change and to evaluate $\gamma$ in equilibrium, which was used in thermodynamic analysis to obtain the zero-frequency $C_{\mathrm{d}}$. In this paper, we will discuss the IL-specific shape of the zero-frequency $C_{\mathrm{d}} v s$. potential curve and the dependence of the curve on IL-constituting ions.

\section{Experimental}

Two ILs, $\left[\mathrm{C}_{2} \mathrm{mim}^{+}\right] \mathrm{BF}_{4}{ }^{-}$and $\left[\mathrm{C}_{8} \mathrm{mim}^{+}\right] \mathrm{BF}_{4}{ }^{-}$, were used in the present study, where $\mathrm{C}_{n} \mathrm{mim}^{+}$denotes 1-alkyl-3-methylimidazolium and $n$ is the number of carbon atoms in the alkyl chain. $\left[\mathrm{C}_{8} \mathrm{mim}^{+}\right] \mathrm{Cl}^{-}$and $\left[\mathrm{C}_{2} \mathrm{mim}^{+}\right] \mathrm{Br}^{-}$were synthesized by mixing 1-methylimidazole (Tokyo Chemical Industry) with 1-chlorooctane (Tokyo Chemical Industry) and 1-bromoethane (Tokyo Chemical Industry), respectively. ${ }^{56}\left[\mathrm{C}_{8} \mathrm{mim}^{+}\right] \mathrm{BF}_{4}{ }^{-}$was prepared ${ }^{57}$ and purified $^{15,58}$ in the same way as literature methods. For the preparation of $\left[\mathrm{C}_{2} \mathrm{mim}^{+}\right] \mathrm{BF}_{4}{ }^{-}$, aqueous solutions of equimolar amounts of $\left[\mathrm{C}_{2} \mathrm{mim}^{+}\right] \mathrm{Br}^{-}$and $\mathrm{Na}^{+} \mathrm{BF}_{4}{ }^{-}$were mixed, followed by removing water using an evaporator. The mixed salts were dissolved in dichloromethane and the precipitated $\mathrm{NaBr}$ was filtered off. $\left[\mathrm{C}_{2} \mathrm{mim}^{+}\right] \mathrm{BF}_{4}{ }^{-}$dissolved in dichloromethane was purified as in the case of $\left[\mathrm{C}_{8} \mathrm{mim}^{+}\right] \mathrm{BF}_{4}{ }^{-}$. Before measurements, volatile impurities were removed from ILs by using a rotary oil pump for more than $6 \mathrm{~h}$ at $50{ }^{\circ} \mathrm{C}$. $\mathrm{Hg}$ was purchased (Aldrich, 99.9999\%), and purified physically by passing it through a PTFE filter twice and then chemically by passing it in $7 \mathrm{wt} \%$ nitric acid in a separating funnel, in which the purified $\mathrm{Hg}$ was kept until the measurements.

A pendant drop method ${ }^{59-61}$ was employed to measure $\gamma$. The details of the apparatus were described in a paper by Kitazumi and Kakiuchi. ${ }^{62}$ The optical cell (width, height, and optical length are 20,40, and $20 \mathrm{~mm}$, respectively) filled with an IL was set in a jacketed holder at $25.0 \pm 0.1{ }^{\circ} \mathrm{C}$. A pendant drop of $\mathrm{Hg}$ hanging from the glass tube with an inner diameter of $2 \mathrm{~mm}$ in the IL was illuminated with paralleled light. An image of the drop was taken using a CCD camera equipped with a telecentric zoom lens. The contour of the drop was extracted from the image by using a homemade program. A theoretical curve calculated using the Bashforth-Adams differential equa$\operatorname{tion}^{63}$ was fitted to the contour of the drop using SALS, a software for the nonlinear least-squares fitting. ${ }^{64}$ Three fitting parameters $R_{0}, \Delta z$, and $\beta$ are the radius of curvature at the origin of the contour of the drop, an error of origin of $z$ axis (vertical direction), and $\beta=\frac{\Delta \rho g R_{0}{ }^{2}}{\gamma}$, respectively, where $\Delta \rho$ and $g$ are the density difference of $\mathrm{Hg}$ and $\mathrm{IL}$ and the acceleration of gravity. The $\rho$ values for $\left[\mathrm{C}_{2} \mathrm{mim}^{+}\right] \mathrm{BF}_{4}{ }^{-}$and $\left[\mathrm{C}_{8} \mathrm{mim}^{+}\right] \mathrm{BF}_{4}{ }^{-}$were measured to be 1.2802 and $1.1009 \mathrm{~g} \mathrm{~cm}^{-3}$, respectively, at $25.0{ }^{\circ} \mathrm{C}$ using a density meter (DA-505, KEM), which agree with those in the literature for $\left[\mathrm{C}_{2} \mathrm{mim}^{+}\right] \mathrm{BF}_{4}{ }^{-65-67}$ and $\left[\mathrm{C}_{8} \mathrm{mim}^{+}\right] \mathrm{BF}_{4}{ }^{-68,69}$ The $\rho$ value for $\mathrm{Hg}$ was adopted to be $13.5336 \mathrm{~g} \mathrm{~cm}^{-3}$ at $25.0{ }^{\circ} \mathrm{C}$ from the literature. ${ }^{70}$ The $\gamma$ values were evaluated from the two fitted parameters, $\beta$ and $R_{0}$, and the fixed parameter, $\Delta \rho$.

The potential at the IL $\mid \mathrm{Hg}$ interface was controlled using a three-electrode electrochemical system. Pt wire was immersed in $\mathrm{Hg}$, which acts as a working electrode (WE), inside the glass tube to externally control the potential. A Ag wire coated with $\mathrm{AgCl}$ was directly immersed in the IL as a quasi-reference electrode (QRE), and a Pt coiled wire as a counter electrode (CE). The potential of the $\mathrm{Hg} \mathrm{WE}$ with respect to the $\mathrm{Ag} / \mathrm{AgCl}$ QRE, denoted as E, was controlled using a PC-controlled potentiostat (HA1010mM1A, Hokuto Denko). At each potential, measurements were continued for sufficiently long time, typically more than $5 \mathrm{~min}$ to equilibrate the interfacial structure at the IL $\mid \mathrm{Hg}$ interface.

The $\gamma$ value that became independent of time was adopted as $\gamma$ in equilibrium at the potential. The number of measurements was 3-20 for each potential.

\section{Results and discussion}

The electrocapillary curve obtained at the $\left[\mathrm{C}_{2} \mathrm{mim}^{+}\right] \mathrm{BF}_{4}{ }^{-} \mid \mathrm{Hg}$ interface is shown in Fig. 1a as solid circles. The $\gamma$ values were successfully measured within the potential window of the $\left[\mathrm{C}_{2} \mathrm{mim}^{+}\right] \mathrm{BF}_{4}{ }^{-} \mid \mathrm{Hg}$ shown in the cyclic voltammogram in Fig. $1 \mathrm{~b}$. The shape of $\gamma$ as a function of $E$ is parabolic, which means that the interfacial excess energy decreases with increase of the absolute value of the interfacial charge density on $\mathrm{Hg},\left|q_{\mathrm{M}}\right|$. The potential at the apex of the parabola is the potential of zero charge, $E_{\mathrm{pzc}}$, where the interface is not charged $\left(q_{\mathrm{M}}=0\right)$. Also shown in Fig. 1a as open circles are data from a previous 


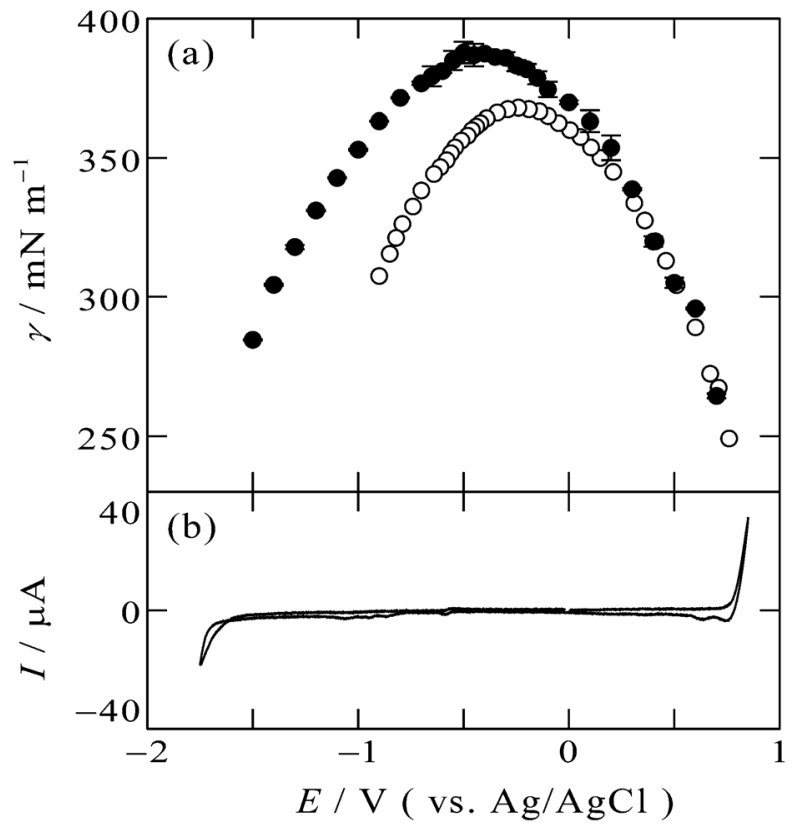

Fig. 1 (a) Electrocapillarity at the $\left[\mathrm{C}_{2} \mathrm{mim}^{+}\right] \mathrm{BF}_{4}{ }^{-} \mid \mathrm{Hg}$ interface measured by the pendant drop method (solid circles) in the present study and by the drop time method (open circles), ${ }^{51}$ with error bars of one standard deviation. (b) Cyclic voltammogram at the $\left[\mathrm{C}_{2} \mathrm{mim}^{+}\right] \mathrm{BF}_{4}{ }^{-} \mid \mathrm{Hg}$ interface with a scan rate of $20 \mathrm{mV} \mathrm{s}^{-1}$

study by Alam et al. using the drop time method $^{51}$ which is a "dynamic" method. The present data using the pendant drop method agree with those using the drop time method at $E \geq 0.3 \mathrm{~V}$, positive side of the parabola. On the other hand, discrepancy is discernible for data from the two methods at $E<0.3 \mathrm{~V}$; the $\gamma$ values using the pendant drop method are greater than those using the drop time method, for more negative potentials.

This discrepancy is ascribable to the ultraslow relaxation of the structure at the $\mathrm{IL} \mid \mathrm{Hg}$ interface. The open circuit potential $E_{\mathrm{OCP}}$ was measured to be around $+0.3 \mathrm{~V}$. When we apply potential around $E_{\mathrm{OCP}}$, the potential difference is small and the EDL structure relatively easily reaches the equilibrium state at the potential, therefore, $\gamma$ from the dynamic method and the static method agree with each other. On the other hand, at negative potentials far from $E_{\mathrm{OCP}}$, the time scale of the drop time method, several seconds, ${ }^{6,48}$ is not long enough for the completion of the ultraslow relaxation, leading to the larger discrepancy at more negative potentials. Another factor we may have to consider for the ultraslow relaxation is asymmetry of the relaxation time to the potential step direction, which we recently found by using surface plasmon resonance at the interface between gold and an IL, trioctylmethylammonium bis(nonafluorobutanesulfonyl)amide. ${ }^{20}$ For the case of the $\mathrm{Au} \mid \mathrm{IL}$ interface, the time constant against the positive step is much slower than that against the negative step, and specific interaction between the ammonium cation and gold surface was considered as a possible reason for the asymmetry. ${ }^{20}$ However, the present case seems to be explained by the opposite tendency: slower time constant for the negative step. The opposite tendency may be caused by another specific interaction between

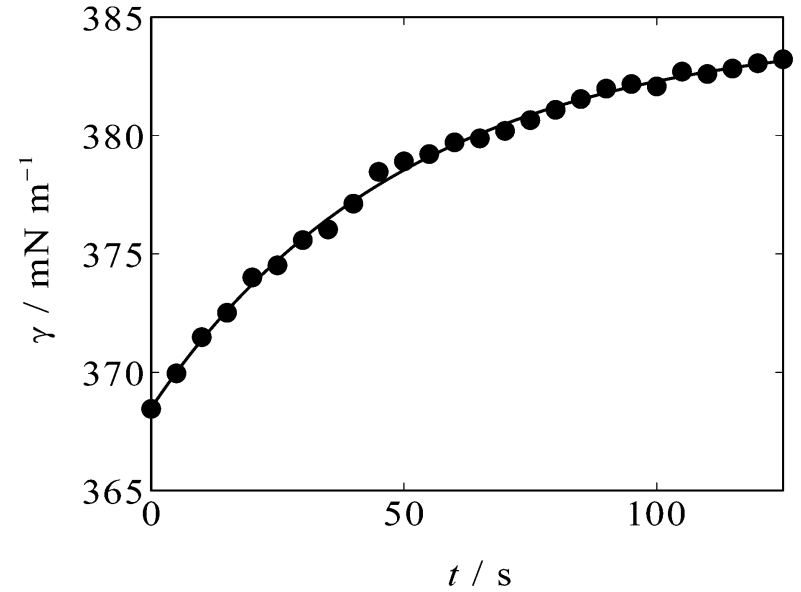

Fig. 2 Time course of $\gamma$ (solid circles) at the $\left[\mathrm{C}_{2} \mathrm{mim}^{+}\right] \mathrm{BF}{ }_{4}^{-} \mid \mathrm{Hg}$ interface when the potential was stepped from OCP $(+0.3 \mathrm{~V})$ to $-0.3 \mathrm{~V}$ at $t=0 \mathrm{~s}$. The solid curve is an exponential decay curve fitted to the data.

different metal $(\mathrm{Hg})$ surface and different ions $\left(\mathrm{C}_{2} \mathrm{mim}^{+}\right.$or $\mathrm{BF}_{4}^{-}$) for the present case.

An example of the time variation of $\gamma$ after the potential step is shown in Fig. 2. One can see that $\gamma$ rises after $t=0 \mathrm{~s}$ when the potential is stepped from OCP $(+0.3 \mathrm{~V}$, positive side of the parabola) to $-0.3 \mathrm{~V}$, near the apex of the parabola. The solid curve in Fig. 2 is an exponential decay curve fitted to the data. The time constant of the decay was found to be $50 \mathrm{~s}$. Such ultraslow relaxation was reported for the electrochemical interfaces of $\mathrm{ILs}^{15-21}$ and the data indicate that the interfacial structure at the $\left[\mathrm{C}_{2} \mathrm{mim}^{+}\right] \mathrm{BF}_{4}{ }^{-} \mid \mathrm{Hg}$ interface also varies in response to the potential perturbation at this time scale.

Another IL, $\left[\mathrm{C}_{8} \mathrm{mim}^{+}\right] \mathrm{BF}_{4}{ }^{-}$, with $\mathrm{C}_{8} \mathrm{mim}^{+}$having a longer alkyl chain than $\mathrm{C}_{2} \mathrm{mim}^{+}$, exhibits similar tendency to $\left[\mathrm{C}_{2} \mathrm{mim}^{+}\right] \mathrm{BF}_{4}{ }^{-}$. Fig. $3 \mathrm{a}$ and $\mathrm{b}$ show the electrocapillary curve and the cyclic voltammogram at the $\left[\mathrm{C}_{8} \mathrm{mim}^{+}\right] \mathrm{BF}_{4}{ }^{-} \mid \mathrm{Hg}$ interface, respectively. This interface also exhibit $E_{\mathrm{OCP}}$ at $+0.3 \mathrm{~V}$, and $\gamma$ around $E_{\mathrm{OCP}}$ determined by the pendant drop method (solid squares) and the drop time method (open squares) is similar, whereas at more negative potentials than $E_{\mathrm{OCP}} \gamma$ obtained by the pendant drop method is greater than that obtained by the drop time method.

The $\gamma$ values in equilibrium obtained using the pendant drop method enable us for the thermodynamic analysis. The differentiation of $\gamma$ with $E$ gives $q_{\mathrm{M}}$, as follows

$$
q_{\mathrm{M}}=-\left(\frac{\partial \gamma}{\partial E}\right)
$$

To numerically differentiate the electrocapillarity data, we adopted local quadratic approximation. Quadratic least squares regression with weight from experimental error was applied for each five consecutive data points of $\gamma$ shown in Fig. 1a and 3a and the slope of the regression curve at the potential of the center data point was evaluated to be $-q_{\mathrm{M}}$ at the potential. The $q_{\mathrm{M}}$ values as a function of $E$ at the $\left[\mathrm{C}_{2} \mathrm{mim}^{+}\right] \mathrm{BF}_{4}{ }^{-} \mid \mathrm{Hg}$ interface and the $\left[\mathrm{C}_{8} \mathrm{mim}^{+}\right] \mathrm{BF}_{4}{ }^{-} \mid \mathrm{Hg}$ interface are shown in Fig. $4 \mathrm{a}$ and $\mathrm{b}$, respectively. The $q_{\mathrm{M}}$ values largely increase with more positive potentials, however, one can find a non-monotonic dependence 


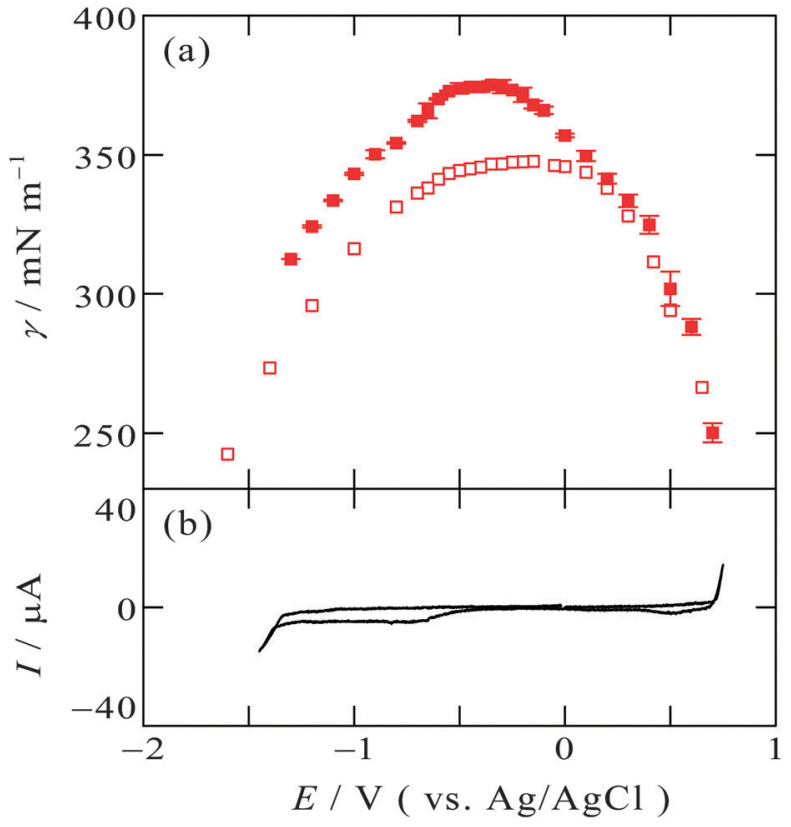

Fig. 3 (a) Electrocapillarity at the $\left[\mathrm{C}_{8} \mathrm{mim}^{+}\right] \mathrm{BF}_{4}{ }^{-} \mid \mathrm{Hg}$ interface measured by the pendant drop method (solid squares) in the present study and by the drop time method (open squares), ${ }^{51}$ with error bars of one standard deviation. (b) Cyclic voltammogram at the $\left[\mathrm{C}_{8} \mathrm{mim}^{+}\right] \mathrm{BF}_{4}{ }^{-} \mid \mathrm{Hg}$ interface with a scan rate of $20 \mathrm{mV} \mathrm{s}^{-1}$

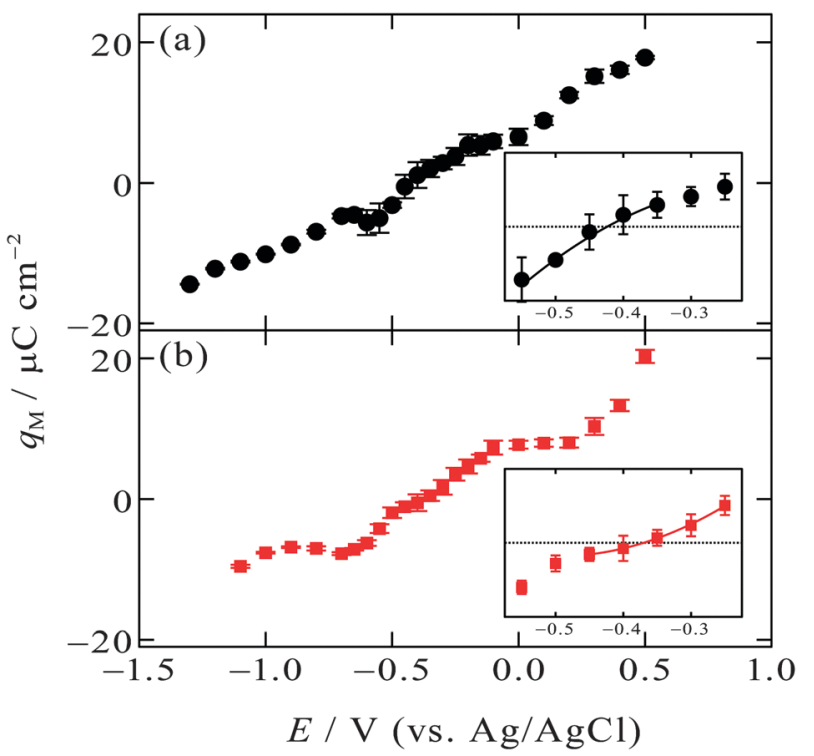

Fig. 4 Surface charge on $\mathrm{Hg}\left(q_{M}\right)$ as a function of the electrode potential (a) at the $\left[\mathrm{C}_{2} \mathrm{mim}^{+}\right] \mathrm{BF}_{4}{ }^{-} \mid \mathrm{Hg}$ interface and (b) at the $\left[\mathrm{C}_{8} \mathrm{mim}^{+}\right] \mathrm{BF}_{4}{ }^{-} \mid \mathrm{Hg}$ interface with error bars of one standard deviation. Inset in each figure is a magnified one around $q_{M}=0$. The solid curves in the insets are from quadratic least squares regression with weights for five consecutive data points around $q_{M}=0$.

in both of the plots. Such a non-monotonic potential dependence of $q_{\mathrm{M}}$ reflects the potential dependence of the zerofrequency $C_{\mathrm{d}}$ as we will see below. Since $E_{\mathrm{pzc}}$ is the potential at $q_{\mathrm{M}}=0$ from its definition, we can evaluate $E_{\mathrm{pzc}}$ from these
Table 1 Potential of zero charge $\left(E_{\mathrm{pzc}}\right)$ at the ionic liquid|mercury interface

\begin{tabular}{ll}
\hline Ionic liquid & $E_{\mathrm{pzc}}{ }^{a} / \mathrm{V}$ \\
\hline$\left[\mathrm{C}_{2} \mathrm{mim}^{+}\right] \mathrm{BF}_{4}{ }^{-}$ & $-0.42 \pm 0.06^{b}$ \\
{$\left[\mathrm{C}_{8} \mathrm{mim}^{+}\right] \mathrm{BF}_{4}{ }^{-}$} & $-0.38 \pm 0.04^{b},-0.45 \pm 0.04^{c}$ \\
${ }^{a}$ With respect to Ag/AgCl QRE. ${ }^{b}$ Present study. ${ }^{c}$ Ref. 71.
\end{tabular}

figures by finding $E$ at $q_{\mathrm{M}}=0$. Insets in Fig. 4 are magnified figures of the $q_{\mathrm{M}} v s$. $E$ plots around $q_{\mathrm{M}}=0$. By using the local quadratic approximation around $q_{\mathrm{M}}=0$, we evaluated $E_{\mathrm{pzc}}$ to be $-0.42 \pm 0.06 \mathrm{~V}$ and $-0.38 \pm 0.04 \mathrm{~V}$ for the $\left[\mathrm{C}_{2} \mathrm{mim}^{+}\right] \mathrm{BF}_{4}{ }^{-} \mid \mathrm{Hg}$ interface and the $\left[\mathrm{C}_{8} \mathrm{mim}^{+}\right] \mathrm{BF}_{4}^{-} \mid \mathrm{Hg}$ interface, respectively (Table 1). The $E_{\mathrm{pzc}}$ for the $\left[\mathrm{C}_{8} \mathrm{mim}^{+}\right] \mathrm{BF}_{4}{ }^{-} \mid \mathrm{Hg}$ interface agrees with $-0.45 \pm 0.04 \mathrm{~V}$, which was measured using the immersion method at the same interface. ${ }^{71}$ These $E_{\mathrm{pzc}}$ data will play a key role as "reference" potentials when we discuss the potential dependence of the zero-frequency $C_{\mathrm{d}}$ below.

The zero-frequency $C_{\mathrm{d}}$ may be written as

$$
C_{\mathrm{d}}=\left(\frac{\partial q_{\mathrm{M}}}{\partial E}\right)
$$

and was evaluated by the numerical differentiation as in the case for $q_{\mathrm{M}}$ described above. Fig. 5 shows the zero-frequency $C_{\mathrm{d}}$ for the $\left[\mathrm{C}_{2} \mathrm{mim}^{+}\right] \mathrm{BF}_{4}{ }^{-} \mid \mathrm{Hg}$ interface (solid circles in Fig. 5a) and the $\left[\mathrm{C}_{8} \mathrm{mim}^{+}\right] \mathrm{BF}_{4}{ }^{-} \mid \mathrm{Hg}$ interface (solid squares in Fig. $5 \mathrm{~b}$ ) with the vertical dotted lines at $E_{\mathrm{pzc}}$. For the $\left[\mathrm{C}_{2} \mathrm{mim}^{+}\right] \mathrm{BF}_{4}{ }^{-} \mid \mathrm{Hg}$ interface (Fig. 5a), the zero-frequency $C_{\mathrm{d}}$ exhibits bell-shape dependence that has one local maximum at $-0.45 \mathrm{~V}$ close to $E_{\mathrm{pzc}}(-0.42 \mathrm{~V})$.

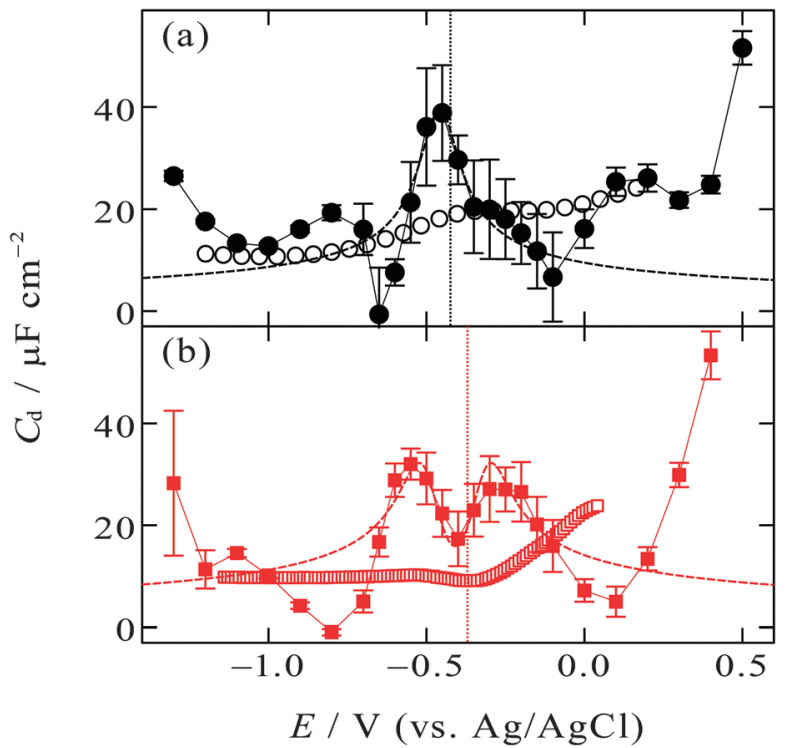

Fig. 5 Zero-frequency differential capacitance (solid circles and solid squares) as a function of the electrode potential (a) at the $\left[\mathrm{C}_{2} \mathrm{mim}^{+}\right] \mathrm{BF}_{4}{ }^{-} \mid \mathrm{Hg}$ interface and (b) at the $\left[\mathrm{C}_{8} \mathrm{mim}^{+}\right] \mathrm{BF}_{4}{ }^{-} \mid \mathrm{Hg}$ interface with error bars of one standard deviation. Vertical dotted lines are at the potential of zero charge. The open circles and squares are high-frequency $(1 \mathrm{kHz})$ differential capacitance obtained from the literature. ${ }^{48,49}$ The dashed lines are fitted curves of eqn (3) to experimental plots within the potential region (a) from -0.15 to $-0.55 \mathrm{~V}$, (b) from -0.1 to $-0.65 \mathrm{~V}$. 
Such a local maximum around $E_{\mathrm{pzc}}$ is opposite tendency to the global minimum at $E_{\mathrm{pzc}}$ predicted by the Gouy-Chapman (GC) model $^{45,46}$ for EDL of electrolyte solutions. In contrast, the bell shape was proposed by recent theories for EDL of ILs. ${ }^{3,33,35}$ The theories explain the reason of the bell shape as follows. To charge up the electrode from $E_{\text {pzc }}$ positively (negatively), cations (anions) at the first ionic layer at the interface should be replaced by anions (cations) coming from bulk, and the replacement of ions decreases available "replacement sites" at the first ionic layer for further charging up. With proceeding the charge up process, the first ionic layer will fully be occupied by anions (cations) and ionic layers that are relatively far from the electrode will be used for the replacement process. Since the capacitance is inversely proportional to the distance between charged "plates" (electrode surface and ionic layer in the present case), the zero-frequency $C_{\mathrm{d}}$ gradually decreases with increasing $\left|E-E_{\mathrm{pzc}}\right|$.

On the other hand, the $\left[\mathrm{C}_{8} \mathrm{mim}^{+}\right] \mathrm{BF}_{4}{ }^{-} \mid \mathrm{Hg}$ interface exhibits camel shape dependence, in which two local maxima exist at negative and positive sides of $E_{\mathrm{pzc}}$ (Fig. $5 \mathrm{~b}$ ). The camel shape was also predicted by the mean field theory for EDL of ILs when the ILs have "compacity", $\eta$, less than $1 / 3 .^{3,33}$ The compacity is a measure of how much the charge on ions can be packed in EDL compared with the bulk condition and defined as $2 c_{0} / c_{\text {max }}$ where $c_{0}$ and $c_{\max }$ are the bulk concentration and the maximal possible local concentration of the charge, respectively. For ILs having a neutral moiety (long alkyl chain in the present case) and thus having low compacity, ions can gather to the interface replacing not counter ions but the neutral moiety, leading to the increase in the zero-frequency $C_{\mathrm{d}}$ with increasing $\left|E-E_{\mathrm{pzc}}\right|$ as expected in the GC model. After neutral moieties in the first ionic layer are depleted due to the replacement, the behavior of the zero-frequency $C_{\mathrm{d}}$ goes back to IL-like decrease instead of GC-like increase with increasing $\left|E-E_{\text {pzc }}\right|$, resulting in the two local maxima in the $C_{\mathrm{d}}$ vs. $E$ plots. The $\mathrm{IL}\left[\mathrm{C}_{8} \mathrm{mim}^{+}\right] \mathrm{BF}_{4}{ }^{-}$is composed of only ions and does not contain molecules, however, the non-charged octyl moiety in $\mathrm{C}_{8} \mathrm{mim}^{+}$can behave as "molecules" that can be replaced by the anions or the charged-moiety of $\mathrm{C}_{8} \mathrm{mim}^{+}$ when the interface becomes charged up. Such behavior was also confirmed by Monte Carlo (MC) simulation of the IL/electrode interface. ${ }^{72,73}$ The study using a coarse-grain model for the ions constituting ILs suggested that ILs without a neutral moiety show bell-shape dependence of $C_{\mathrm{d}}$ whereas ILs having a neutral moiety show camel-shape dependence. A series of theoretical and simulation studies well accord with the present experimental results for zero-frequency $C_{\mathrm{d}}$ where $\left[\mathrm{C}_{2} \mathrm{mim}^{+}\right] \mathrm{BF}_{4}{ }^{-}$without a long alkyl chain shows bell-shape dependence and $\left[\mathrm{C}_{8} \mathrm{mim}^{+}\right] \mathrm{BF}_{4}{ }^{-}$with a long alkyl chain shows camel-shape dependence (Fig. 5). On the other hand, this is not the case for recent MD simulation studies on the dependence of zero-frequency $C_{\mathrm{d}}$ on the alkyl chain length for $\mathrm{C}_{n} \mathrm{mim}^{+}$-based ILs of bis(trifluoromethanesulfonyl)amide $\left(\mathrm{TFSA}^{-}\right)^{41}$ or bis(fluorosulfonyl)amide (FSA $\left.{ }^{-}\right)^{43}$ at the atomically flat or atomically rough graphite interface. The results did not show the bell-shape to camel-shape transition except for $\left[\mathrm{C}_{n} \mathrm{mim}^{+}\right]\left[\mathrm{FSA}^{-}\right]$ at the atomically rough graphite interface. No transition for $\left[\mathrm{C}_{n} \mathrm{mim}^{+}\right]\left[\mathrm{TFSA}^{-}\right]$and $\left[\mathrm{C}_{n} \mathrm{mim}^{+}\right]\left[\mathrm{FSA}^{-}\right]$at the atomically flat graphite interface may be due to larger size and therefore a larger neutral moiety for $\mathrm{TFSA}^{-}$and $\mathrm{FSA}^{-}$than $\mathrm{BF}_{4}{ }^{-}$. A future experimental study on the dependence of the zero-frequency $C_{\mathrm{d}}$ on IL anions using the pendant drop method at the atomically flat $\mathrm{Hg}$ interface will enable further discussion. Note that it is zero-frequency $C_{\mathrm{d}}$ that can be predicted by theoretical and simulation studies and that was measured by the pendant drop method in the present study. $C_{\mathrm{d}}$ at a non-zero frequency measured using EIS should be different from zero-frequency $C_{\mathrm{d}}$ when considering ultraslow relaxation at IL interfaces with a time constant slower than the EIS frequency (e.g. $1 \mathrm{kHz})$. To compare the difference, in Fig. $5, C_{\mathrm{d}}$ data at $1 \mathrm{kHz}$ using EIS are shown as open symbols, which were measured for the $\left[\mathrm{C}_{2} \mathrm{mim}^{+}\right] \mathrm{BF}_{4}{ }^{-} \mid \mathrm{Hg}$ interface ${ }^{48}$ and the $\left[\mathrm{C}_{8} \mathrm{mim}^{+}\right] \mathrm{BF}_{4}{ }^{-} \mid \mathrm{Hg}$ interface $^{49}$ by Alam et al. One can see less featured shape of the EIS $C_{\mathrm{d}}$ compared with the zero-frequency $C_{\mathrm{d}}$ (solid symbols), which is likely due to the ultraslow relaxation of the structure in EDL of ILs.

The mean field theory ${ }^{33,34}$ proposed an analytical solution for the potential dependence of the zero-frequency $C_{\mathrm{d}}$ for EDL of ILs as

$$
C_{\mathrm{d}}=C_{\mathrm{d}, 0} \frac{\cosh \left(\frac{u_{0}}{2}\right)}{2 \eta \sinh \mathrm{h}^{2}\left(\frac{u_{0}}{2}\right)+1} \sqrt{\frac{2 \eta \sinh ^{2}\left(\frac{u_{0}}{2}\right)}{\ln \left(2 \eta \sinh ^{2}\left(\frac{u_{0}}{2}\right)+1\right)}}
$$

where $C_{\mathrm{d}, 0}$ is $C_{\mathrm{d}}$ at $E=E_{\mathrm{pzc}}$, and $u_{0}=\frac{F\left(E-E_{\mathrm{pzc}}\right)}{R T}$ is the normalized potential with the Faraday constant $F$, the gas constant $R$, and the absolute temperature $T$. Note that the mean field theory does not incorporate local electrostatic interaction between ions that leads to the overscreening effect. The overscreening effect was predicted to be non-negligible ${ }^{33}$ and was found in MD simulation, ${ }^{36,39,44,74,75}$ some of which suggested that the overscreening effect is remarkable especially for small $\left|u_{0}\right| .^{36,74,75}$ At this stage, we only have the mean field theory to be compared with the present data. Although it was found that MD results qualitatively approved the mean field theory, $^{72,74}$ a MD (or MC) simulation for the present $\mathrm{Hg} \mid \mathrm{IL}$ interface system is required to quantitatively investigate the overscreening effect, and such a simulation study is now in progress in our laboratory. We fitted the theoretical curve of eqn (3) to the experimental data to extract the compacity for these ILs. For the fitting we limited the experimental data only for $E \sim E_{\mathrm{pzc}},-0.15$ to $-0.55 \mathrm{~V}$ for $\left[\mathrm{C}_{2} \mathrm{mim}^{+}\right] \mathrm{BF}_{4}{ }^{-}$and -0.1 to $-0.65 \mathrm{~V}$ for $\left[\mathrm{C}_{8} \mathrm{mim}^{+}\right] \mathrm{BF}_{4}{ }^{-}$, because of unpredicted behavior in the plots (will be described below) outside the potential region. Although the potential dependence of the compacity that stems from different ionic compacities for the cation and anion in IL was also proposed, ${ }^{33}$ we did not use it because of the limitation of the potential region. The fitted curves are shown in Fig. 5 as the dashed lines. The fitted $\eta$ value for $\left[\mathrm{C}_{2} \mathrm{mim}^{+}\right] \mathrm{BF}_{4}{ }^{-}$is 0.5 ( $E_{\mathrm{pzc}}$ and $C_{\mathrm{d}, 0}$ are $-0.46 \mathrm{~V}$ and $40 \mu \mathrm{F} \mathrm{cm}{ }^{-2}$, respectively). The compacity value agrees with $\mathrm{MD}$ simulation result, $\eta=0.43$, for a model IL composed of spherical ions without a neutral moiety. ${ }^{3,36}$ The compacity for $\left[\mathrm{C}_{8} \mathrm{mim}^{+}\right] \mathrm{BF}_{4}{ }^{-}$is 0.05 
( $E_{\mathrm{pzc}}$ and $C_{\mathrm{d}, 0}$ are $-0.41 \mathrm{~V}$ and $16 \mu \mathrm{F} \mathrm{cm}^{-2}$, respectively). As expected, the value is less than $1 / 3$, the demarcation value between bell-shape and camel-shape behaviors. ${ }^{33}$ Since the compacity is unity minus the sum of void fraction and the fraction of neutral moieties in IL-ions, we can understand the lower compacity for $\left[\mathrm{C}_{8} \mathrm{mim}^{+}\right] \mathrm{BF}_{4}{ }^{-}$having a longer neutral alkyl chain than that for $\left[\mathrm{C}_{2} \mathrm{mim}^{+}\right] \mathrm{BF}_{4}{ }^{-}$. However, the value 0.05 for $\left[\mathrm{C}_{8} \mathrm{mim}^{+}\right] \mathrm{BF}_{4}{ }^{-}$seems too low compared with 0.5 for $\left[\mathrm{C}_{2} \mathrm{mim}^{+}\right] \mathrm{BF}_{4}{ }^{-}$even when considering that the neutral octyl chain lowers the compacity for $\left[\mathrm{C}_{8} \mathrm{mim}^{+}\right] \mathrm{BF}_{4}{ }^{-}$. The lower compacity is probably due to a greater void fraction in $\left[\mathrm{C}_{8} \mathrm{mim}^{+}\right] \mathrm{BF}_{4}{ }^{-}$than $\left[\mathrm{C}_{2} \mathrm{mim}^{+}\right] \mathrm{BF}_{4}{ }^{-}$. The idea is supported by a study on theoretical analysis of the surface tension and the void fraction of ILs, where ILs of cations with a longer alkyl chain tend to have a greater void fraction. ${ }^{76}$

After the fitting, features that were not predicted in the mean field theory are clear by comparing the experimental data (solid symbols) and the fitted curves (dashed lines) in Fig. 5. For both $\left[\mathrm{C}_{2} \mathrm{mim}^{+}\right] \mathrm{BF}_{4}{ }^{-}$and $\left[\mathrm{C}_{8} \mathrm{mim}^{+}\right] \mathrm{BF}_{4}{ }^{-}$, when increasing $\left|E-E_{\mathrm{pzc}}\right|$ from $E=E_{\mathrm{pzc}}$ one can see a decrease in experimental zero-frequency $C_{\mathrm{d}}$ after the local maxima to values lower than fitted curves of eqn (3). Although we are not sure the reason for the low zerofrequency $C_{\mathrm{d}}$, one possibility is stabilization of ionic layers at the potential region due to local ion-ion interaction that are not taken into account in the mean field theory. Solid-like ionic layers of ILs at interfaces have been reported by several groups. ${ }^{77-80}$ Such stabilization could lead to little ion exchange in EDL for charging up and thus to low capacitance. An existence of the energy barrier for the ion exchange in EDL of ILs was also verified using surface-enhanced IR absorption spectroscopy. ${ }^{81}$ Another unpredicted feature is the increase in zero-frequency $C_{\mathrm{d}}$ when $E$ goes far from $E_{\mathrm{pzc}}$ both in the positive and negative directions. Such increase has been found even for non-zero frequency $C_{\mathrm{d}}$ by EIS at the potential window limit of the $\mathrm{Hg}$ interface of $\left[\mathrm{C}_{2} \mathrm{mim}^{+}\right] \mathrm{BF}_{4}{ }^{-5}$ and other IL. ${ }^{6}$ A MD simulation on the graphite interface of $\left[\mathrm{C}_{4} \mathrm{mim}^{+}\right] \mathrm{BF}_{4}{ }^{-}$showed a similar trend in zero-frequency $C_{\mathrm{d}} \cdot{ }^{42}$ The increase in zerofrequency $C_{\mathrm{d}}$ at the potential regions far from $E_{\mathrm{pzc}}$ may remind electrochemists of the zero-frequency $C_{\mathrm{d}}$ behavior at the interface between $\mathrm{Hg}$ and aqueous electrolyte solutions (W) ${ }^{82}$ For the $\mathrm{Hg} \mid \mathrm{W}$ interface, the Gouy-Chapman model, ${ }^{45,46}$ which is also a mean-field theory, well explains the $C_{\mathrm{d}}$ behavior only around $E_{\mathrm{pzc}}$. On the other hand, at potentials far from $E_{\mathrm{pzc}}$, the increase in zero-frequency $C_{\mathrm{d}}$ with increasing $\left|E-E_{\mathrm{pzc}}\right|$ was confirmed, which cannot be explained by the Gouy-Chapman model. This interesting phenomenon at the $\mathrm{Hg} \mid \mathrm{W}$ interface has stimulated theoretical studies of EDL and several possible reasons have been proposed such as electrostriction of EDL, ${ }^{83}$ interfacial complexation of $\mathrm{Hg}$ with an electrolyte anion, ${ }^{83}$ orientational change of water molecules in the inner layer, ${ }^{84}$ and densification of the inner layer. ${ }^{85}$ In spite of considerable theoretical efforts, the reason for the $C_{\mathrm{d}}$ increase has not been fully clarified yet (see a recent review on EDL for details ${ }^{86}$ ). One may associate the orientational change of water molecules in the inner layer at the $\mathrm{Hg} \mid \mathrm{W}$ interface ${ }^{84}$ with ion behavior at the $\mathrm{Hg} \mid \mathrm{IL}$ interface; the orientational changes of the ions in the inner layer would be one of the possible reasons for the $C_{\mathrm{d}}$ increase.
To probe any change in the interfacial structure depending on the potential, we used in situ spectroscopic ellipsometry for the interface between $\mathrm{Hg}$ and four ILs including $\left[\mathrm{C}_{8} \mathrm{mim}^{+}\right] \mathrm{BF}_{4}{ }^{-}$. The results showed a potential-dependent structure at the interface and were well reproduced with a model incorporating ionic layers whose density is higher than bulk at $E \gg E_{\mathrm{pzc}}{ }^{71}$ Therefore, it is likely that the ionic layers at the interface become densified reacting to the strong electric field at the interface when the interface is highly charged at potentials far from $E_{\mathrm{pzc}}$.

\section{Conclusions}

In a recent review on EDL in ILs by Fedorov and Kornyshev, ${ }^{3}$ they described "The fact that impedance measurements cannot reliably assess equilibrium characteristics is not a problem of the EDL theory that operates with equilibrium properties, but rather a problem of experimental techniques available these days." This paper presented that one experimental technique, the pendant drop method, is available to measure zero-frequency $C_{\mathrm{d}}\left(C_{\mathrm{d}}\right.$ in equilibrium) for the electrochemical interface of ILs, where it is unlikely to be possible for EIS to assess the quantity. The measured zero-frequency $C_{\mathrm{d}}$ at the $\mathrm{Hg} \mid \mathrm{IL}$ interface demonstrates peculiar potential dependences: bell shape or camel shape depending on the cation species of ILs. Such behaviors were predicted in 2007 by mean field theory, ${ }^{33}$ however, they have not been confirmed with experimental zero-frequency capacitance, although some studies on non-zero frequency capacitance measured by EIS have supported the theory. ${ }^{7,72}$ It should be noted that the pendant drop method has some drawbacks; it limits the electrode material (should be liquid) and the experiment is neither easy or fast compared with EIS. Nevertheless, the method still provides valuable experimental data that can be compared with and could improve the theory of EDL in ILs.

\section{Acknowledgements}

This work was partly supported by a Grant-in-Aid for Scientific Research (no. 26410149) and by a grant from the UBE Foundation (N.N.). We appreciate Dr Yuki Kitazumi for building the apparatus of the pendant drop method and for encoding the analysis program.

\section{References}

1 M. Armand, F. Endres, D. R. Macfarlane, H. Ohno and B. Scrosati, Nat. Mater., 2009, 8, 621-629.

2 Electrochemical Aspects of Ionic Liquids, ed. H. Ohno, Wiley, Hoboken, 2nd edn, 2011.

3 M. V. Fedorov and A. A. Kornyshev, Chem. Rev., 2014, 114, 2978-3036.

4 R. J. Gale and R. A. Osteryoung, Electrochim. Acta, 1980, 25, 1527-1529.

5 C. Nanjundiah, S. F. McDevitt and V. R. Koch, J. Electrochem. Soc., 1997, 144, 3392-3397. 
6 M. T. Alam, M. M. Islam, T. Okajima and T. Ohsaka, Electrochem. Commun., 2007, 9, 2370-2374.

7 M. M. Islam, M. T. Alam and T. Ohsaka, J. Phys. Chem. C, 2008, 112, 16568-16574.

8 M. M. Islam, M. T. Alam, T. Okajima and T. Ohsaka, J. Phys. Chem. C, 2009, 113, 3386-3389.

9 Y. Z. Su, Y. C. Fu, J. W. Yan, Z. B. Chen and B. W. Mao, Angew. Chem., Int. Ed., 2009, 48, 5148-5151.

10 B. Bozzini, A. Bund, B. Busson, C. Humbert, A. Ispas, C. Mele and A. Tadjeddine, Electrochem. Commun., 2010, 12, 56-60.

11 J. P. Zheng, P. C. Goonetilleke, C. M. Pettit and D. Roy, Talanta, 2010, 81, 1045-1055.

12 L. Siinor, K. Lust and E. Lust, J. Electrochem. Soc., 2010, 157, F83-F87.

13 T. F. Esterle, D. Sun, M. R. Roberts, P. N. Bartlett and J. R. Owen, Phys. Chem. Chem. Phys., 2012, 14, 3872-3881.

14 M. Proskurnin and A. Frumkin, Trans. Faraday Soc., 1935, 31, 110-115.

15 Y. Yasui, Y. Kitazumi, R. Ishimatsu, N. Nishi and T. Kakiuchi, J. Phys. Chem. B, 2009, 113, 3273-3276.

16 I. Bou-Malham and L. Bureau, Soft Matter, 2010, 6, 4062-4065.

17 S. Makino, Y. Kitazumi, N. Nishi and T. Kakiuchi, Electrochem. Commun., 2011, 13, 1365-1368.

18 B. Roling, M. Drüschler and B. Huber, Faraday Discuss., 2012, 154, 303-311.

19 M. Drüschler, N. Borisenko, J. Wallauer, C. Winter, B. Huber, F. Endres and B. Roling, Phys. Chem. Chem. Phys., 2012, 14, 5090-5099.

20 N. Nishi, Y. Hirano, T. Motokawa and T. Kakiuchi, Phys. Chem. Chem. Phys., 2013, 15, 11615-11619.

21 A. Uysal, H. Zhou, G. Feng, S. S. Lee, S. Li, P. Fenter, P. T. Cummings, P. F. Fulvio, S. Dai, J. K. McDonough and Y. Gogotsi, J. Phys. Chem. C, 2014, 118, 569-574.

22 V. Lockett, R. Sedev, J. Ralston, M. Horne and T. Rodopoulos, J. Phys. Chem. C, 2008, 112, 7486-7495.

23 M. Gnahm, T. Pajkossy and D. M. Kolb, Electrochim. Acta, 2010, 55, 6212-6217.

24 M. Drüschler, B. Huber and B. Roling, J. Phys. Chem. C, 2011, 115, 6802-6808.

25 T. Pajkossy and D. M. Kolb, Electrochem. Commun., 2011, 13, 284-286.

26 Y. Su, J. Yan, M. Li, M. Zhang and B. Mao, J. Phys. Chem. C, 2013, 117, 205-212.

27 L. Siinor, R. Arendi, K. Lust and E. Lust, J. Electroanal. Chem., 2013, 689, 51-56.

28 J. Wallauer, M. Drüschler, B. Huber and B. Roling, Z. Naturforsch., B: Chem. Sci., 2013, 68, 1143-1153.

29 T. R. Gore, T. Bond, W. Zhang, R. W. J. Scott and I. J. Burgess, Electrochem. Commun., 2010, 12, 1340-1343.

30 M. Drüschler, B. Huber, S. Passerini and B. Roling, J. Phys. Chem. C, 2010, 114, 3614-3617.

31 M. T. Alam, J. Masud, M. M. Islam, T. Okajima and T. Ohsaka, J. Phys. Chem. C, 2011, 115, 19797-19804.

32 H. Wang and L. Pilon, Electrochim. Acta, 2012, 63, 55-63.

33 A. A. Kornyshev, J. Phys. Chem. B, 2007, 111, 5545-5557.
34 M. S. Kilic, M. Z. Bazant and A. Ajdari, Phys. Rev. E: Stat., Nonlinear, Soft Matter Phys., 2007, 75, 021502.

35 K. B. Oldham, J. Electroanal. Chem., 2008, 613, 131-138.

36 M. V. Fedorov and A. A. Kornyshev, Electrochim. Acta, 2008, 53, 6835-6840.

37 G. Feng, J. S. Zhang and R. Qiao, J. Phys. Chem. C, 2009, 113, 4549-4559.

38 J. Vatamanu, O. Borodin and G. D. Smith, J. Am. Chem. Soc., 2010, 132, 14825-14833.

39 G. Feng, J. Huang, B. G. Sumpter, V. Meunier and R. Qiao, Phys. Chem. Chem. Phys., 2011, 13, 14723-14734.

40 X. Si, S. Li, Y. Wang, S. Ye and T. Yan, ChemPhysChem, 2012, 13, 1671-1676.

41 J. Vatamanu, O. Borodin, D. Bedrov and G. D. Smith, J. Phys. Chem. C, 2012, 116, 7940-7951.

42 Z. Hu, J. Vatamanu, O. Borodin and D. Bedrov, Phys. Chem. Chem. Phys., 2013, 15, 14234-14247.

43 Z. Hu, J. Vatamanu, O. Borodin and D. Bedrov, Electrochim. Acta, 2014, 145, 40-52.

44 M. Sha, Q. Dou, F. Luo, G. Zhu and G. Wu, ACS Appl. Mater. Interfaces, 2014, 6, 12556-12565.

45 L. G. Gouy, J. Phys., 1910, 9, 457-468.

46 D. L. Chapman, Philos. Mag., 1913, 25, 475-481.

47 M. M. Islam, M. T. Alam, T. Okajima and T. Ohsaka, J. Phys. Chem. B, 2007, 111, 12849-12856.

48 M. T. Alam, M. M. Islam, T. Okajima and T. Ohsaka, J. Phys. Chem. C, 2007, 111, 18326-18333.

49 M. T. Alam, M. Islam, T. Okajima and T. Ohsaka, J. Phys. Chem. C, 2008, 112, 2601-2606.

50 F. Silva, C. Gomes, M. Figueiredo, R. Costa, A. Martins and C. M. Pereira, J. Electroanal. Chem., 2008, 622, 153-160.

51 M. T. Alam, M. M. Islam, T. Okajima and T. Ohsaka, J. Phys. Chem. C, 2009, 113, 6596-6601.

52 R. Costa, C. M. Pereira and F. Silva, Phys. Chem. Chem. Phys., 2010, 12, 11125-11132.

53 M. Ammam, D. Di Caprio and L. Gaillon, Electrochim. Acta, 2012, 61, 207-215.

54 R. Costa, C. M. Pereira and F. Silva, RSC Adv., 2013, 3, 11697-11706.

55 A. Lewandowski, T. Majkowski and M. Galinski, Z. Naturforsch., A: Phys. Sci., 2009, 64, 263-268.

56 C. M. Gordon, J. D. Holbrey, A. R. Kennedy and K. R. Seddon, J. Mater. Chem., 1998, 8, 2627-2636.

57 X. Creary and E. D. Willis, Org. Synth., 2005, 82, 166-169.

58 M. J. Earle, C. M. Gordon, N. V. Plechkova, K. R. Seddon and T. Welton, Anal. Chem., 2007, 79, 758-764.

59 J. Andreas, E. Hauser and W. Tucker, J. Phys. Chem., 1938, 42, 1001-1019.

60 H. H. Girault, D. J. Schiffrin and B. D. V. Smith, J. Electroanal. Chem., 1982, 137, 207-217.

61 T. Kakiuchi, M. Nakanishi and M. Senda, Bull. Chem. Soc. Jpn., 1988, 61, 1845-1851.

62 Y. Kitazumi and T. Kakiuchi, Langmuir, 2009, 25, 8062-8068.

63 F. Bashforth and J. C. Adams, An Attempt to Test the Theories of Capillary Action, Cambridge University Press, London, 1883. 
64 T. Nakagawa and Y. Oyanagi, in Recent Developments in Statistical Inference and Data Analysis, ed. K. Matusita, North-Holland, Amsterdam, 1980, pp. 221-225.

65 E. Rilo, J. Pico, S. Garcia-Garabal, L. M. Varela and O. Cabeza, Fluid Phase Equilib., 2009, 285, 83-89.

66 J. Vila, P. Ginés, E. Rilo, O. Cabeza and L. M. Varela, Fluid Phase Equilib., 2006, 247, 32-39.

67 A. Stoppa, O. Zech, W. Kunz and R. Buchner, J. Chem. Eng. Data, 2010, 55, 1768-1773.

68 T. Singh and A. Kumar, J. Chem. Thermodyn., 2008, 40, 417-423.

69 J. Restolho, A. P. Serro, J. L. Mata and B. Saramago, J. Chem. Eng. Data, 2009, 54, 950-955.

70 D. Ambrose, Metrologia, 1990, 27, 245-247.

71 N. Nishi, J. Uchiyashiki, R. Oogami and T. Sakka, Thin Solid Films, 2014, 571, 735-738.

72 M. V. Fedorov, N. Georgi and A. A. Kornyshev, Electrochem. Commun., 2010, 12, 296-299.

73 N. Georgi, A. A. Kornyshev and M. V. Fedorov, J. Electroanal. Chem., 2010, 649, 261-267.

74 M. V. Fedorov and A. A. Kornyshev, J. Phys. Chem. B, 2008, 112, 11868-11872.
75 V. Ivaništšev, S. O'Connor and M. V. Fedorov, Electrochem. Commun., 2014, 48, 61-64.

76 C. Larriba, Y. Yoshida and J. F. de la Mora, J. Phys. Chem. B, 2008, 112, 12401-12407.

77 Y. Yokota, T. Harada and K. Fukui, Chem. Commun., 2010, 46, 8627-8629.

78 R. Köhler, J. Restolho, R. Krastev, K. Shimizu, J. N. Canongia Lopes and B. Saramago, J. Phys. Chem. Lett., 2011, 2, 1551-1555.

79 X. Zhang, L. Lu and Y. Cai, Langmuir, 2012, 28, 9593-9600.

80 M. Rosa Castillo, J. M. Fraile and J. A. Mayoral, Langmuir, 2012, 28, 11364-11375.

81 K. Motobayashi, K. Minami, N. Nishi, T. Sakka and M. Osawa, J. Phys. Chem. Lett., 2013, 4, 3110-3114.

82 D. C. Grahame, Chem. Rev., 1947, 41, 441-501.

83 R. Watts-Tobin, Philos. Mag., 1961, 6, 133-153.

84 R. Guidelli, in Trends in Interfacial Electrochemistry, ed. A. F. Silva, Reidel, Dordrecht, 1986, vol. 179, pp. 387-452.

85 J. R. MacDonald and C. A. Barlow, Jr., J. Chem. Phys., 1962, 36, 3062-3080.

86 B. B. Damaskin and O. A. Petrii, J. Solid State Electrochem., 2011, 15, 1317-1334. 